\title{
Refined Staging for Chorioretinopathy in Long-Chain 3-Hydroxyacyl Coenzyme A Dehydrogenase Deficiency
}

\author{
Tiina Tyni Tuuli Immonen Päivi Lindahl Anna Majander Tero Kivelä \\ Department of Pediatric Neurology and Ophthalmology, Helsinki University Central Hospital, Helsinki, Finland
}

\section{Key Words}

Pigmentary retinopathy, classification - Fatty acid

oxidation $\cdot$ Inherited metabolic disorder

\begin{abstract}
Objective: Neonatal screening and earlier diagnosis have improved the prognosis of long-chain 3-hydroxyacyl coenzyme A dehydrogenase (LCHAD) deficiency, which causes a need to refine the staging of the pigmentary chorioretinopathy and thus improve monitoring and comparability of patients under dietary therapy. Methods: Seven children with LCHAD deficiency caused by homozygous G1528C mutation attended sequential fundus photography for stage 2 chorioretinopathy in 1997-2006. After arranging 21 pairs of fundus photographs according to the severity of the fundus changes, the images best representing 3 different grades of pigmentary deposits (P1-P3) and retinal pigment epithelial (RPE) atrophy (A1-A3) were chosen as reference photographs. To evaluate the substaging, 29 pairs of photographs were graded according to the reference photographs. Results: In the assessment of pigmentary deposits, the 3 ophthalmologists agreed in $41 \%$ and differed by a single substage in $45 \%$ of instances (combined weighted $\mathrm{k}$ statistic was 0.38 , indicating moderate agreement). In pairwise comparisons, the weighted $\mathrm{k}$ statistic ranged from 0.31 to 0.56 (agree-
\end{abstract}

ment, $71-81 \%)$. In the assessment of RPE atrophy, all 3 raters agreed in $17 \%$ and 2 raters in $70 \%$ of instances (combined $\mathrm{K}$ statistic 0.018 , indicating poor agreement). Discussion: Despite variation in imaging techniques and limitations in the visual assessment of fundus photographs, the agreement obtained in grading the pigmentary deposits was comparable to that reported for photographic grading of retinopathy of prematurity. We recommend photographic documentation and substaging based on reference photographs in the follow-up of LCHAD retinopathy. The refined staging allows a more detailed assessment on the progression of the retinopathy and optimization of the therapeutic protocols in individual patients and between centres using different therapeutic protocols.

Copyright $\odot 2012$ S. Karger AG, Basel

Deficiencies of the mitochondrial trifunctional protein (MTP) are currently the only known defects of mitochondrial fatty acid $\beta$-oxidation associated with a retinopathy [1]. They are included in neonatal screening programmes, because these defects can be alleviated with a high-carbohydrate, low-fat diet and avoidance of fasting [2].

Long-chain 3-hydroxyacyl coenzyme A dehydrogenase (LCHAD) deficiency is the most frequent type of

\section{KARGER \\ Fax +41613061234 \\ E-Mail karger@karger.ch}

www.karger.com
(C) 2012 S. Karger AG, Basel

$0030-3747 / 12 / 0482-0075 \$ 38.00 / 0$

Accessible online at:

www.karger.com/ore
Tuuli Immonen, MD

Department of Pediatric Neurology, Helsinki University Central Hospital PO Box 280

FI-00290 Helsinki (Finland)

Tel. +358 9 4711, E-Mail Tuuli.Immonen@ hus.fi 
Table 1. Clinical staging based on ophthalmological findings of patients with LCHAD deficiency

\begin{tabular}{lllll}
\hline Stage & Fundus & Vision & ERG/VEP & Fluorescein angiography \\
\hline 1 & Normal or pale & Normal & Normal & Unknown \\
\hline 2 & $\begin{array}{l}\text { Hypopigmentation, pigment } \\
\text { clumping particularly in the } \\
\text { macula }\end{array}$ & Normal & $\begin{array}{l}\text { Progressively } \\
\text { low ERG, } \\
\text { normal VEP }\end{array}$ & $\begin{array}{l}\text { Delayed choroidal filling, drop-out of } \\
\text { choriocapillary lobules, no blockade of } \\
\text { the choroidal background fluorescence }\end{array}$ \\
\hline 3 & $\begin{array}{l}\text { Progressive chorioretinal atrophy } \\
\text { in the posterior pole, relative } \\
\text { sparing of the central macula }\end{array}$ & $\begin{array}{l}\text { Paracentral scotoma, } \\
\text { progressive myopia, de- } \\
\text { teriorated colour vision }\end{array}$ & $\begin{array}{l}\text { Unrecordable } \\
\text { ERG }\end{array}$ & $\begin{array}{l}\text { Progressive occlusion of choriocapillary } \\
\text { and middle-sized choroidal vessels }\end{array}$ \\
\hline 4 & $\begin{array}{l}\text { Total atrophy of the posterior } \\
\text { pole, posterior staphyloma, } \\
\text { sparing of the peripheral fundus }\end{array}$ & Central scotoma & $\begin{array}{l}\text { Unrecordable } \\
\text { ERG, relatively } \\
\text { normal VEP }\end{array}$ & $\begin{array}{l}\text { Only the largest vessels are spared in the } \\
\text { central fundus }\end{array}$ \\
\hline
\end{tabular}

$\mathrm{ERG}=$ Electroretinography; VEP = visual evoked potentials.

MTP defect [3]. The chorioretinopathy associated with it appears during the first year of life as pigmentary deposits in the central fundus, coinciding with metabolic crises characterized by hypoglycaemia, hepatopathy, cardiomyopathy, muscle hypotonia and fat accumulation in affected tissues $[1,4]$.

The chorioretinopathy is one of the manifestations which determine the quality of life in long-term survivors of MTP deficiencies. At least when the diagnosis and dietary therapy are delayed, it can progress to atrophy of the central part of the choroid and retina, low vision, visual field defects, nyctalopia, colour vision defects and progressive myopia $[1,4]$. Prompt dietary therapy may apparently halt or delay the progression of the chorioretinopathy $[1,4,6]$.

To aid the follow-up, we have presented a clinical staging system for the ophthalmological changes of LCHAD deficiency (table 1) [5]. In stage 1, the fundus is similar to the normal, often pale fundus of the newborn. Stage 2 is characterized by pigment aggregates with or without areas of hypopigmentation at the level of the retinal pigment epithelium (RPE), especially in the macula. In stage 3 , progressive chorioretinal atrophy and scleral staphyloma appear in the posterior pole but spare the peripheral fundus and fovea. Stage 4 signifies atrophy extending to the fovea.

Most of our patients diagnosed today, when MTP deficiencies are fairly well known, are classified initially as stage 2 , and few appear to progress to stages 3 and 4, provided that metabolic crises are avoided. To allow a more sensitive detection of the fundus changes, we investigated the possibility of dividing stage 2 in substages. Such a refined classification would detect milder changes and allow comparison of outcomes between centres using different types of dietary therapy. The optimal way of monitoring the retinopathy of infants and small children would be a combination of functional (corneal electroretinography, ERG) and imaging studies (fundus photographs), but unfortunately good-quality follow-up studies in infants and small children require anaesthesia.

\section{Subjects and Methods}

\section{Eligibility Criteria}

Eligible to this study were all Finnish children who had LCHAD deficiency whose chorioretinopathy had not progressed to stage 3 at diagnosis, and who had undergone sequential fundus photography as part of their review examinations from 1997 to 2006. All the patients had the homozygous G1528C (E474Q) mutation [1]. Of 7 eligible patients, all were enrolled into this study, which followed the tenets of the Declaration of Helsinki. The human studies complied with the institutional review board approval for the human studies.

\section{Fundus Photography}

The fundus photographs were obtained during routine review appointments under general anaesthesia and full pupillary dilatation until the age of 3-4 years and without anaesthesia thereafter using 1 of 4 digital imaging systems, depending on the age of the child and the review period: a conventional non-contact fundus camera (TRC-50X, Topcon, Tokyo, Japan; 9 pairs of images), two generations of a contact wide-angle camera with transpupillary illumination (RetCam 120, Massie Research Laboratories, Plesanton, Calif., USA, and RetCam II, Clarity Medical Systems, Plesanton, Calif., USA; 11 pairs), and a contact wide-angle camera 

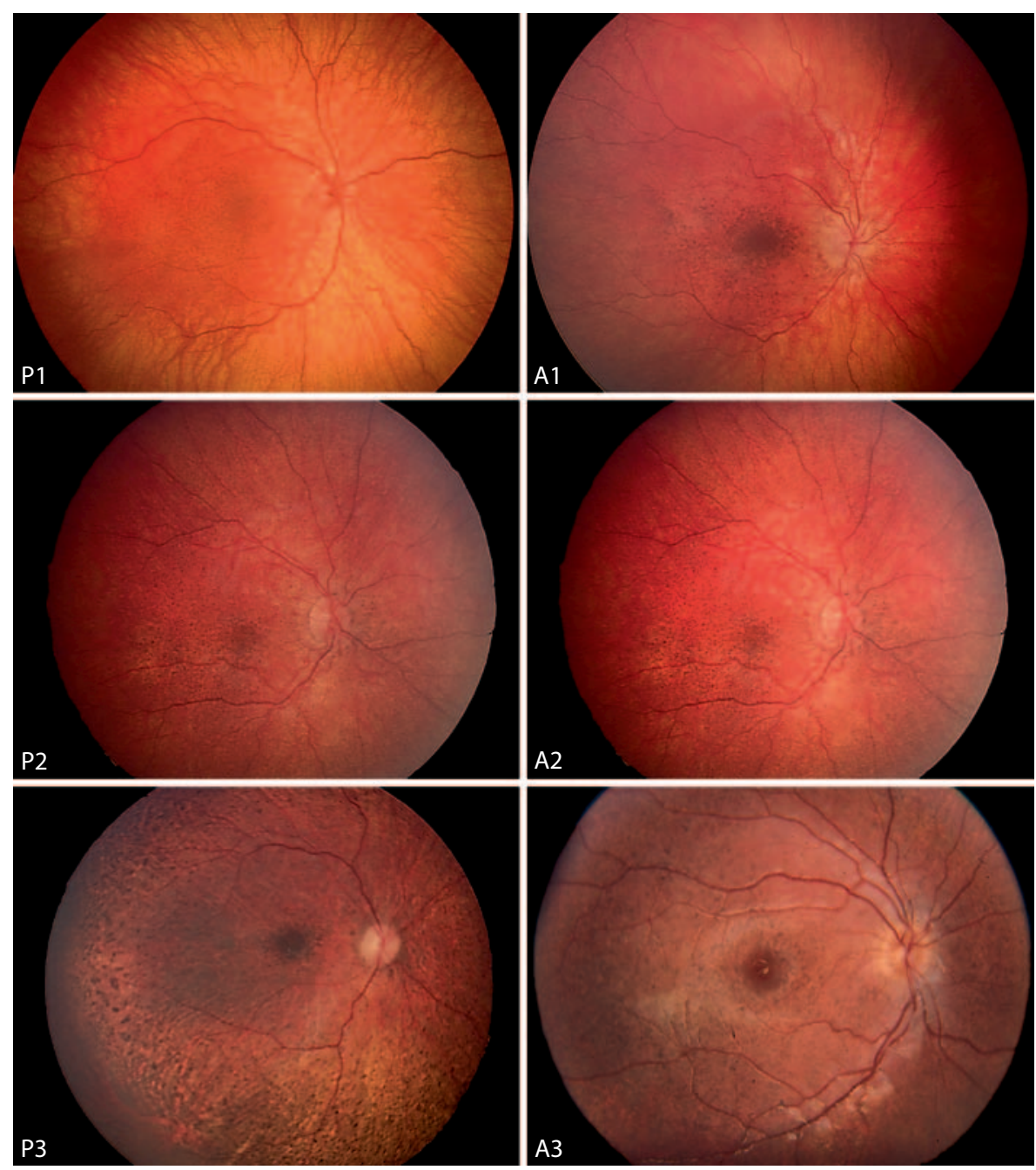

Fig. 1. Images representing the grades of pigmentary deposits (P1-P3) and RPE atrophy (A1-A3).

with transscleral illumination (Panoret 1000, Medibell Medical Vision Technologies, Haifa, Israel; 1 pair). The fundus photographs were printed out on a photo quality ink jet paper to the size of $13 \times 20 \mathrm{~cm}$.

\section{Formation of the Substages}

Technically adequate, representative colour fundus photographs of both eyes (total, 21 pairs of photographs) taken at different review appointments and chosen to include the optic disc, macula and surrounding posterior pole were assessed. Two paediatric ophthalmologists (P.L. and T.K.) and paediatric neurologists (T.I. and T.T.) independently arranged the photographs in as many groups of similar grade as they desired, according to increasing severity of the fundus changes. The pairs were presented in a random order, masked as to the date of photography and to the age and identity of the child. Three raters had a decade of experience in evaluating children with LCHAD deficiency; the fourth had no prior experience. The sorting was repeated 2-3 days later. Each photograph was assigned a score which corresponded to the number and sequence of groups formed by the rater (a score of 1 was assigned to the images which formed the group with least fundus changes, a score of 2 to the next group, and so on).

Because the chorioretinopathy may manifest as pigmentary deposits, atrophy of the RPE or both, two parallel grading systems were considered desirable. Consequently, 3 images best representing clearly separate, advancing grades of pigmentary deposits (P1-P3) and RPE atrophy (A1-A3), respectively, were chosen as reference photographs (fig. 1).

\section{Evaluation of the Substages}

In the second phase, 8 additional pairs of photographs from the same patients were added to the series to be evaluated (total, 29 pairs of photographs). The pairs were presented in a random order in a masked fashion and independently assigned to substages $\mathrm{P} 1-\mathrm{P} 3$ and $\mathrm{A} 1-\mathrm{A} 3$ by 3 paediatric ophthalmologists (the first had seen all the patients, the second had seen several of them, and the third had no previous experience of patients with LCHAD deficiency). Before grading, the raters attended an instruction ses- 
sion in which the reference photographs and the substaging system were discussed.

Ratings which deviated from one another were discussed in a consensus meeting to obtain a final rating for each pair of photographs, which were then linked with the identity and age of each patient at the time of photography, and compared with patient records.

\section{Statistical Methods}

Interrater agreement was assessed with the weighted $\mathrm{k}$ statistic (STATA 11, Stat Corp, College Station, Tex., USA) using standard weighing.

\section{Results}

\section{Formation of the Substages}

The score for an individual fundus image per rater, calculated as the mean of 2 rating sessions, varied from 1.0 to 6.0 for all 4 raters (table 2). The median scores assigned by the two paediatric ophthalmologists and paediatric neurologists were 3.5 and 3.0 (mean, 3.5 and 3.0) and 4.5 and 3.0 (mean, 4.2 and 3.2), respectively. The paediatric neurologist without prior experience in chorioretinopathy was unable to rate 2 images.

The 6 separate groups, independently formed by all 4 raters, suggested that the severity of fundus changes could be divided reliably in at least 3 substages. A mean score from 1.0 to 2.0 was designated substage 1 (7 images), a score from 3.0 to 4.0 was designated substage 2 ( 7 images), and a higher score (8 images) was designated substage 3.

When this scheme was retrospectively applied to the scores of the 4 raters, the 2 ophthalmologists would have agreed on 13 pairs and differed by 2 substages in 2 instances (agreement, 76\%; weighted $\mathrm{k}, 0.46$ ), the 2 paediatric neurologists would have agreed on 6 pairs and differed by 2 substages in 5 instances (agreement, 53\%; weighted $\mathrm{k}, 0.06$ ), and the 2 most experienced graders (an ophthalmologist and a paediatric neurologist) would have agreed on 9 pairs and would never have differed by more than 1 substage (agreement, $71 \%$; weighted $\mathrm{k}, 0.28$ ).

From photographs representing the 3 substages, the more experienced ophthalmologist and paediatric neurologist selected by consensus 2 sets of 3 images (fig. 1), paying first attention to the number of the pigmentary deposits (P1-P3) and then to the extent of RPE atrophy (A1-A3), to serve as reference photographs.

\section{Evaluation of the Substages}

When 29 pairs of images were rated according to the reference photographs, the 3 ophthalmologists agreed on the substage based on pigmentary deposits in 12 pairs
Table 2. The mean scores of 21 pairs of fundus photographs of 7 patients with stage 2 chorioretinopathy of LCHAD deficiency assigned by 2 paediatric ophthalmologists (PO) and paediatric neurologists $(\mathrm{PN})$ masked to the age of the patient and the date of photography

\begin{tabular}{|c|c|c|c|c|c|c|c|c|c|c|}
\hline \multirow[t]{2}{*}{$\begin{array}{l}\text { Image } \\
\text { No. }\end{array}$} & \multicolumn{4}{|c|}{ Score assigned by rater } & \multirow[t]{2}{*}{$\begin{array}{l}\text { Mean } \\
\text { score }\end{array}$} & \multirow{2}{*}{$\begin{array}{l}\text { Pro- } \\
\text { posed } \\
\text { substage }\end{array}$} & \multicolumn{4}{|c|}{$\begin{array}{l}\text { Retrospective } \\
\text { substage }\end{array}$} \\
\hline & PO1 & $\mathrm{PO} 2$ & PN1 & $\mathrm{PN} 2$ & & & PO1 & $\mathrm{PO} 2$ & PN1 & PN2 \\
\hline 5 & 1 & 1.5 & 1 & 5.5 & 2.3 & 1 & 1 & 1 & 1 & 3 \\
\hline 10 & 1.5 & 1 & 3.5 & 1 & 1.8 & 1 & 1 & 1 & 2 & 1 \\
\hline 13 & 1 & 1.5 & 3.5 & 1 & 1.8 & 1 & 1 & 1 & 2 & 1 \\
\hline 15 & 1 & 1.5 & 3.5 & 1 & 1.8 & 1 & 1 & 1 & 2 & 1 \\
\hline 4 & 2 & 1.5 & 2 & 2 & 1.9 & 1 & 1 & 1 & 1 & 1 \\
\hline 11 & 3 & 2 & 3 & 2 & 2.5 & 1 & 2 & 1 & 2 & 1 \\
\hline 12 & 3 & 2 & 4.5 & 2 & 2.9 & 2 & 2 & 2 & 3 & 2 \\
\hline 14 & 4.5 & 1.5 & 3 & - & 3.0 & 2 & 3 & 1 & 2 & - \\
\hline 9 & 3 & 3 & 4.5 & 2 & 3.1 & 2 & 2 & 2 & 3 & 1 \\
\hline 1 & 3.5 & 3 & 5 & 2 & 3.4 & 2 & 2 & 2 & 3 & 1 \\
\hline 16 & 3.5 & 3 & 5 & 2 & 3.4 & 2 & 2 & 2 & 3 & 1 \\
\hline 7 & 5.5 & 2 & 3.5 & 3 & 3.5 & 2 & 3 & 1 & 2 & 2 \\
\hline 21 & 3 & 4 & 5 & 4 & 4.0 & 2 & 2 & 2 & 3 & 2 \\
\hline 2 & 6 & 3 & 4 & - & 4.3 & 3 & 3 & 2 & 2 & - \\
\hline 8 & 3 & 6 & 3 & 6 & 4.5 & 3 & 2 & 3 & 2 & 3 \\
\hline 17 & 4 & 4 & 5 & 5 & 4.5 & 3 & 2 & 2 & 3 & 3 \\
\hline 19 & 4.5 & 4 & 5 & 5 & 4.6 & 3 & 3 & 2 & 3 & 3 \\
\hline 20 & 5 & 4 & 6 & 4 & 4.8 & 3 & 3 & 2 & 3 & 2 \\
\hline 22 & 5 & 5 & 6 & 4 & 5.0 & 3 & 3 & 3 & 3 & 2 \\
\hline 18 & 5 & 5 & 6 & 4.5 & 5.1 & 3 & 3 & 3 & 3 & 3 \\
\hline 3 & 5.5 & 5 & 5.5 & 5 & 5.3 & 3 & 3 & 3 & 3 & 3 \\
\hline
\end{tabular}

The first rater in both specialties had more experience in the assessment of LCHAD chorioretinopathy than the second rater. - = Rating not available.

(41\%; table 3). Two raters agreed in 14 instances (45\%), and all raters disagreed in 4 instances (14\%). The combined weighted $\mathrm{K}$ statistic was 0.38 , indicating moderate agreement.

In pairwise comparisons, the weighted $\mathrm{k}$ statistic was 0.48 and 0.31 (agreement, 76 and $71 \%$, respectively) for 2 pairs of raters which included the one most experienced in LCHAD chorioretinopathy, indicating fair and moderate agreement, respectively. These 2 pairs differed by 2 substages in their evaluation in 4 and 3 instances, respectively. The weighted $\mathrm{k}$ statistic was 0.56 for the third pair of raters (agreement, 81\%) with least experience in LCHAD chorioretinopathy, who never differed by 2 substages in their evaluation, indicating fair agreement.

When the 29 pairs of images were graded for RPE atrophy, the 3 raters agreed on the substage of 5 pairs (17\%), 
Table 3. Substages assigned to 29 pairs of fundus photographs of 7 patients with stage 2 chorioretinopathy of LCHAD deficiency by paediatric ophthalmologists (PO) masked to the age of the patient and the date of photography

\begin{tabular}{|c|c|c|c|c|c|c|c|c|}
\hline \multirow[t]{2}{*}{ Image No. } & \multicolumn{4}{|c|}{ Pigmentary deposits } & \multicolumn{4}{|c|}{ RPE atrophy } \\
\hline & PO1 & $\mathrm{PO} 2$ & $\mathrm{PO} 3$ & consensus & PO1 & $\mathrm{PO} 2$ & $\mathrm{PO} 3$ & consensus \\
\hline 1 & P3 & P3 & P3 & P3 & A3 & A3 & A3 & A3 \\
\hline 2 & $\mathrm{P} 2$ & P3 & P3 & P3 & A2 & A2 & A3 & $\mathrm{A} 2$ \\
\hline 3 & P3 & P3 & P3 & P3 & $\mathrm{A} 1$ & A3 & A3 & A3 \\
\hline 4 & $\mathrm{P} 1$ & $\mathrm{P} 1$ & $\mathrm{P} 1$ & $\mathrm{P} 1$ & A1 & A2 & A2 & $\mathrm{A} 2$ \\
\hline 6 & $\mathrm{P} 2$ & $\mathrm{P} 1$ & $\mathrm{P} 2$ & $\mathrm{P} 2$ & A2 & A3 & A3 & A2 \\
\hline 7 & $\mathrm{P} 2$ & $\mathrm{P} 2$ & $\mathrm{P} 2$ & $\mathrm{P} 2$ & $\mathrm{~A} 2$ & A1 & $\mathrm{A} 2$ & A1 \\
\hline 8 & $\mathrm{P} 2$ & $\mathrm{P} 2$ & P3 & $\mathrm{P} 2$ & A3 & A3 & A3 & A3 \\
\hline 9 & $\mathrm{P} 2$ & P3 & $\mathrm{P} 2$ & $\mathrm{P} 2$ & A2 & A3 & A3 & A3 \\
\hline 10 & P1 & $\mathrm{P} 1$ & $\mathrm{P} 2$ & $\mathrm{P} 1$ & $\mathrm{~A} 2$ & A2 & A3 & A3 \\
\hline 11 & $\mathrm{P} 2$ & $\mathrm{P} 2$ & $\mathrm{P} 2$ & $\mathrm{P} 2$ & A2 & A2 & $\mathrm{A} 2$ & A2 \\
\hline 12 & $\mathrm{P} 2$ & P2 & P2 & P2 & A3 & A2 & A3 & A3 \\
\hline 13 & P2 & $\mathrm{P} 2$ & $\mathrm{P} 1$ & P1 & A3 & A1 & A2 & A2 \\
\hline 14 & P2 & P1 & P2 & P2 & A2 & A2 & A3 & A2 \\
\hline 15 & P2 & P2 & P1 & P1 & A3 & A1 & $\mathrm{A} 2$ & A2 \\
\hline 16 & P2 & P3 & P3 & P3 & A2 & A3 & A3 & A3 \\
\hline 17 & P3 & P3 & P2 & P3 & A2 & A3 & A2 & A2 \\
\hline 18 & P3 & P3 & P3 & P3 & A2 & A3 & $\mathrm{A} 2$ & A2 \\
\hline 19 & P3 & P3 & $\mathrm{P} 2$ & P3 & A3 & A3 & A3 & A3 \\
\hline 20 & P3 & P3 & P3 & P3 & A2 & A3 & A2 & A2 \\
\hline 21 & P3 & P3 & $\mathrm{P} 2$ & P2 & A2 & A3 & $\mathrm{A} 2$ & A2 \\
\hline 22 & P3 & P3 & P3 & P3 & A2 & A3 & A2 & A2 \\
\hline 23 & P1 & P3 & P3 & P3 & A3 & A3 & A1 & A3 \\
\hline 24 & P1 & P3 & P3 & P3 & A3 & A3 & A1 & A3 \\
\hline 25 & P2 & P3 & P3 & P3 & A3 & A3 & A1 & A3 \\
\hline 26 & P1 & P3 & P3 & P3 & A2 & A2 & A2 & A2 \\
\hline 27 & P1 & P3 & $\mathrm{P} 2$ & P2 & A2 & A2 & A1 & A2 \\
\hline 28 & P1 & P1 & P1 & P1 & A2 & A3 & A1 & A2 \\
\hline 29 & P1 & P1 & P1 & P1 & A3 & A3 & A1 & A2 \\
\hline 30 & P1 & P1 & P1 & P1 & A2 & A3 & A1 & A2 \\
\hline
\end{tabular}

Raters are arranged by decreasing experience in the assessment of LCHAD chorioretinopathy.

2 raters agreed on 20 pairs (70\%), and all raters disagreed on 4 pairs (10\%; table 3$)$. The 3 raters differed by 2 substages in 9 instances (31\%). The combined $\mathrm{k}$ statistic was 0.018 , indicating poor agreement.

Combining the consensus ratings with masked clinical data revealed logical stability, progression or regression between substages $\mathrm{P} 1$ and $\mathrm{P} 2$ in 4 of the 6 enrolled patients who had more than one pair of photographs available (table 4). In patient 7, the first fundus photographs at the age of 8-12 years were graded as $\mathrm{P} 3$, but 4 years later they were repeatedly and systematically rated as P1. Clinically, the pigmentary deposits which pro-
Table 4. Consensus substages of 29 pairs of fundus photographs of 7 patients with stage 2 chorioretinopathy of LCHAD deficiency arranged chronologically by patient

\begin{tabular}{|c|c|c|c|}
\hline Patients & $\begin{array}{l}\text { Year of } \\
\text { photography }\end{array}$ & $\begin{array}{l}\text { Pigmentary } \\
\text { deposits }\end{array}$ & $\begin{array}{l}\text { RPE } \\
\text { atrophy }\end{array}$ \\
\hline \multirow[t]{2}{*}{1} & 2003 & P3 & A2 \\
\hline & 2005 & P3 & A3 \\
\hline 2 & 2002 & $\mathrm{P} 1$ & A2 \\
\hline \multirow[t]{4}{*}{3} & 2003 & $\mathrm{P} 2$ & A2 \\
\hline & $2005^{1}$ & $\mathrm{P} 2$ & A1 \\
\hline & $2005^{1}$ & $\mathrm{P} 2$ & A3 \\
\hline & 2006 & $\mathrm{P} 2$ & A3 \\
\hline \multirow[t]{3}{*}{4} & 2002 & $\mathrm{P} 1$ & A3 \\
\hline & 2005 & $\mathrm{P} 2$ & A2 \\
\hline & 2006 & $\mathrm{P} 2$ & A3 \\
\hline \multirow[t]{5}{*}{5} & 2002 & $\mathrm{P} 2$ & A2 \\
\hline & $2004^{1}$ & $\mathrm{P} 1$ & A2 \\
\hline & $2004^{1}$ & $\mathrm{P} 1$ & A2 \\
\hline & $2005^{1}$ & P3 & A3 \\
\hline & $2005^{1}$ & P3 & A3 \\
\hline \multirow[t]{6}{*}{6} & 1998 & $\mathrm{P} 3$ & A2 \\
\hline & 1999 & P3 & A3 \\
\hline & 2002 & P3 & A2 \\
\hline & 2003 & P3 & A2 \\
\hline & 2005 & $\mathrm{P} 2$ & $\mathrm{~A} 2$ \\
\hline & 2006 & P3 & A2 \\
\hline \multirow[t]{8}{*}{7} & 1998 & P3 & A3 \\
\hline & 1999 & $\mathrm{P} 3$ & A3 \\
\hline & 2000 & P3 & A3 \\
\hline & 2002 & P3 & A2 \\
\hline & 2003 & $\mathrm{P} 2$ & A2 \\
\hline & 2004 & $\mathrm{P} 1$ & $\mathrm{~A} 2$ \\
\hline & 2005 & $\mathrm{P} 1$ & $\mathrm{~A} 2$ \\
\hline & 2006 & $\mathrm{P} 1$ & A2 \\
\hline
\end{tabular}

For consensus rating, see table 3.

${ }^{1}$ Taken at the same review appointment with 2 different imaging systems. gressed initially might regress in the long term. In the remaining 2 patients, up to 2 chronological inconsistencies were noted.

Logical progression of substages A1-A2 was noted in 2 of the 6 enrolled patients who had more than one pair of photographs available (table 4). In 3 patients, the consensus substage showed 1-2 chronological inconsistencies, and in 1 patient the substages regressed illogically. The atrophic changes of the RPE can only progress or remain stationary in the long term.

Two pairs of photographs of patient 3 had been taken during the same review appointment with 2 different 
cameras. The pigmentary deposits were rated to the same consensus substage (P2), whereas consensus ratings of $\mathrm{RPE}$ atrophy differed by 2 substages (A1 and A3).

\section{Discussion}

Although a low-fat high-carbohydrate diet dramatically improves the prognosis of mitochondrial fatty acid $\beta$-oxidation defects, the optimal composition of the diet and the long-term prognosis of the retinopathy, peripheral neuropathy and cardiomyopathy are not known. To be able to modify the dietary therapy, it is important to monitor the most sensitive organ affected in these disorders. Pigmentary retinopathy is one of the earliest manifestations of LCHAD deficiency, which may lead to a severe retinal degeneration during the first years of life.

Initial overall rating of digital fundus images from 7 children with LCHAD deficiency to refine the staging of the associated chorioretinopathy suggested that stage 2 of the original staging system might be subdivided into at least 3 substages of pigmentary changes and fundus atrophy. Subsequent evaluation of the substaging based on pigmentary deposits documented moderate agreement between 3 ophthalmologists who rated the images. Pairwise comparisons produced $71-81 \%$ agreement and $\mathrm{k}$ statistics ranging from 0.31 to 0.56 , indicating moderate to fair agreement. These measures of agreement were highest for those pairs of raters who were most similar in their experience in evaluating patients with LCHAD deficiency. Comparison of consensus substages with patient charts showed that for 4 of 6 patients with sequential fundus images and for 1 patient who had been imaged during the same visit with 2 different systems, the ratings were logical over time, supporting clinical validity of the substaging system.

A grading based on RPE atrophy showed poor agreement by statistical criteria. Twice as many images rated for atrophy returned a difference of 2 substages as compared to rating based on pigmentary deposits. When attempting to reach consensus, it became obvious that discrepancies in rating atrophy often resulted from uneven exposure of photographs between eyes, appointments and imaging techniques. Even the consensus substages were often inconsistent over time. It is clearly more challenging to assess the extent of atrophic than pigmentary changes from fundus photographs. Especially, peripheral shading of the fundus exaggerated any central RPE atrophy. An individual, age- and race-dependent variation in pigmentation of the fundus is remarkable, which also ex- plains the difficulties in classification of the pigmentary and particularly of the atrophic fundus changes. In practice, it may be easier to assess progression of the fundus changes of the same patient than to classify the changes in individual fundus photographs. The knowledge of the initial state of the fundus changes most probably reduces the variation when grading the atrophic fundus changes.

Systematic use of a standardized imaging system and illumination level in follow-up of MTP deficiencies would be advisable, but is not easy to implement for children representing a wide age range. To minimize the influence of technical problems during later analysis of the fundus changes, it would be best to select the most representative fundus images for the archives during the ophthalmological examination. Not all variations in the classification are dependent on technical problems, however. How borderline cases that fall close to the next substage are rated also has an influence.

Recently, the interexpert agreement of grading retinopathy of prematurity from wide-angle fundus images taken during routine care with the same RetCam II system as was used in the present study has been evaluated $[7,8]$. When rated by 22 experts to 2 categories based on the presence or absence of plus disease, the $\mathrm{K}$ statistic was fair to moderate for the majority of the raters, ranging from 0.21 to 0.60 for $68 \%$ of them. In the second study, the $\mathrm{k}$ statistic ranged from 0.29 to 0.69 for 11 experts. Taking into account that a single imaging method was used in the retinopathy of prematurity studies whereas the protocol varied by the age of the patient and the review period in our study, we conclude that ophthalmologists can grade pigmentary deposits of the chorioretinopathy of LCHAD deficiency reasonably accurately by matching them with the reference photographs. Because the interrater agreement between paediatric neurologists in the initial rating was lower, the refined system was evaluated and is recommended for use primarily by ophthalmologists.

Careful long-term review of patients who receive dietary therapy for LCHAD deficiency most probably provides important data on the efficacy of this treatment. A valid and reliable substaging of the fundus changes combined with corneal ERG would be ideal in the follow-up of patients. Although ERG is useful in the follow-up of LCHAD retinopathy, our earlier follow-up data has shown that corneal ERG may be normal even in infants who have widespread fundus pigmentation, atrophy of the central retina including RPE and choroidal atrophy. Despite the obvious limitations of imaging techniques and visual assessment based on reference images, we rec- 
ommend photographic documentation of the fundus changes and application of a common staging system in the ophthalmological review of patients with MTP deficiency. Such an approach should improve the reproducibility of the staging of the associated chorioretinopathy. At any rate, use of reference photographs should be a better option than reverting to verbal descriptions in recording the stage of retinopathy and its progression. The substaging of pigmentary changes needs to be tested further using an independent data set, especially because the evaluation was based in part on the same photographs and raters which were used in its formation.

\section{Acknowledgements}

We are grateful for the support of the Academy of Finland, Arvo and Lea Ylppö Foundation, the Finnish Medical Foundation, Evald and Hilda Nissi Foundation, Oskar Öflund Foundation and TYH 4115, Helsinki, Finland.

\section{Disclosure Statement}

No authors have any financial/conflicting interests to disclose. The funding organizations had no role in the design or conduct of this research.

\section{References}

$>1$ Tyni T, Kivelä T, Lappi M, et al: Ophthalmologic findings in long-chain 3-hydroxyacylCoA dehydrogenase deficiency caused by the G1528C mutation. A new type of hereditary metabolic chorioretinopathy. Ophthalmology 1998;105:810-824.

$\checkmark 2$ Sander J, Sander S, Steuerwald U, et al: Neonatal screening for defects of the mitochondrial trifunctional protein. Mol Genet Metab 2005;85:108-114.

3 Ijlst L, Wanders RJA, Ushikubo S, et al: Molecular basis of long-chain 3-hydroxyacylCoA dehydrogenase deficiency: identification of the major disease-causing mutation in the alpha-subunit of the mitochondrial trifunctional protein. Biochim Biophys Acta 1994;1215:347-350.
4 Fahnehjelm K, Holmström G, Haglind C, et al: Ocular characteristic in 10 children with long-chain 3-hydroxyacyl-CoA dehydrogenase deficiency: a cross-sectional study with long-term follow-up. Acta Ophthalmol Scand 2007;86:329-337.

$\checkmark 5$ Tyni T, Pihko H, Kivelä T: Ophthalmic pathology in long-chain 3-hydroxyacyl-CoA dehydrogenase deficiency caused by the G1528C mutation. Curr Eye Res 1998;17: 551-559.
6 Gillingham MB, Weleber RG, Neuringer M Effect of optimal dietary therapy upon visual function in children with long-chain 3-hydroxyacyl CoA dehydrogenase and trifunctional protein deficiency. Mol Genet Metab 2005;86:124-133.

7 Chiang MF, Gelman R, Jiang L, et al: Plus disease in retinopathy of prematurity: an analysis of diagnostic performance. Trans Am Ophthalmol Soc 2007;105:73-85.

8 Koreen S, Gelman R, Martinez-Perez ME, et al: Evaluation of a computer-based system for plus-disease diagnosis in retinopathy of prematurity. Ophthalmology 2007;114:5967. 